\section{COMMENTARY Ice Age Floods National Geologic Trail}

New legislation was presented to Congress in January 2005 for a proposed Ice Age Floods National Geologic Trail, to be located over a four-state (Montana, Idaho, Washington, and Oregon) region of the Pacific Northwest. The proposed trail would be managed by the National Park Service (NPS) and use existing public lands to tell the story of the cataclysmic Ice Age floods, beginning with the pioneering work of legendary geologists J Harlen Bretz and Joseph T. Pardee. These men, and many other geologists since, uncovered a fascinating story of repeated outburst floods, mostly from Glacial Lake Missoula, that occurred periodically throughout the Pleistocene. Ice Age floods, moving at up to $80 \mathrm{mph}$ and lasting a week or less, carved a complex network of dry coulees and cataracts, while depositing 400-ft-tall sediment bars-many with giant current ripples. These unique landforms and many more, including misplaced, ice-rafted erratics up to almost $1000 \mathrm{ft}$ above valley floors, occur all along the 700-mile-long route of the floods.

Members of the public and the scientific community are coming together in support of this first-of-its-kind National Geologic Trail, which will span the area between the Clark Fork River of Montana and the mouth of the Columbia River. A grassroots movement began in 1994, when Pacific Northwest geologists and interested citizens joined forces to organize the Ice Age Floods Institute (IAFI), a nonprofit educational organization dedicated to bringing the story of repeated cataclysmic floods to the public. In 1999, the NPS, recognizing the significance of these obscure events, commissioned an environmental assessment and study of alternatives to tell the story of the floods. The recommendation for an Ice Age Floods National Geologic Trail came as a result of the NPS and IAFI study. The study called for the NPS to coordinate with the IAFI as well as state and local governments, public, tribal, and private interpretive efforts to tell a cohesive story.

Recently, the National Geologic Trail idea has received widespread bipartisan support and attention of legislators from the Pacific Northwest delegation. Two separate bills were introduced to each house of Congress calling for adoption of an Ice Age Floods National Geologic Trail. Congressman Doc Hastings (R-Wash.) introduced the bill to the House, while Maria Cantwell (D-Wash.) introduced it to the Senate. This "park without boundaries" would include kiosks and signs placed on the existing network of public lands and roadways that pass through the floods region. Wording in the bills limits purchase or donation of private property from assenting landowners to 25 acres or less.

The region could reap tremendous socioeconomic benefits from such a trail with relatively little capital expenditure. A National Geologic Trail would attract interested parties from around the region as well as across the country. The benefits from tourism and development would bring a much-needed boost to rural economies along the floods route. The trail would not only increase public awareness and appreciation of their geologic heritage, but also inspire young minds-perhaps providing a catalyst for a new generation of earth scientists.

The Ice Age Floods National Geologic Trail bill awaits debate in Congress, which could happen soon. Those members of the geologic community in favor should write their U.S. Congressman promptly, informing them of the bill and expressing their support. This could be just the beginning in a series of National Geologic Trails; certainly many other parts of the nation are just as deserving and have their own stories to tell.

To view the NPS Ice Age Floods Study of Alternatives and Environmental Assessment go to www.nps.gov/iceagefloods. For more information on the Ice Age Floods Institute and Ice Age Floods National Geologic Trail legislation visit www. iceagefloodsinstitute.org.

\section{Bruce Bjornstad, Lake Lewis Chapter, IAFI Licensed Geologist/Hydrogeologist Senior Research Scientist, Pacific Northwest National Laboratory}

Photos taken in eastern Washington State by Bruce Bjornstad. Top: an icerafted granodiorite erratic near the Columbia River. Bottom: Frenchman Coulee in the Channeled Scabland.

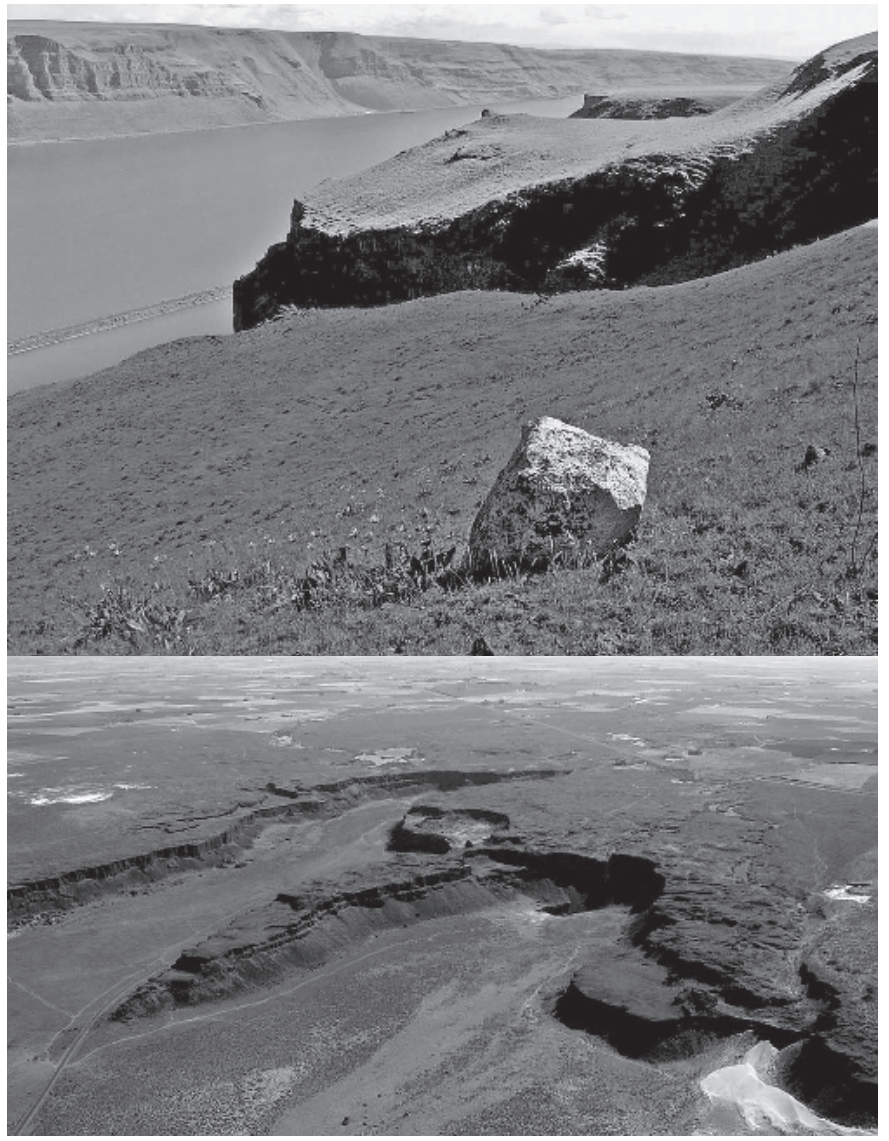

